\title{
Damage to common plumbing materials caused by overwintering Leptoglossus occidentalis (Hemiptera: Coreidae)
}

\author{
Sarah L. Bates ${ }^{1}$ \\ Department of Entomology, New York State Agricultural Experiment Station, Cornell \\ University, 630 West North Street, Geneva, New York 14456, United States of America
}

The western conifer seed bug, Leptoglossus occidentalis Heidemann (Hemiptera: Coreidae), is a polyphagous pest of coniferous trees (Hedlin et al. 1981). Native to western North America, the seed bug has expanded its range to include eastern Canada and the United States (McPherson et al. 1990; Gall 1992; Marshall 1992; Ridge-O'Connor 2001; Bates 2002) and was recently introduced into Europe (Taylor et al. 2001). Both adults and nymphs feed by inserting their stylets into cones and digesting the contents of developing seeds, and they can cause serious economic losses in high-value seed orchards (Strong et al. 2001; Bates et al. 2002; Bates and Borden 2005). In late summer and early fall, L. occidentalis adults seek sheltered locations in which to aggregate and overwinter, including tree cavities, animal nests, and manmade structures (Hussey 1953; Koerber 1963; Gall 1992; Blatt 1994). Aggregations appear to be mediated by a male-produced pheromone (Blatt and Borden 1996) and may contain a few to over 2000 individuals (Blatt 1994). Seed bugs overwintering in houses and other buildings have been previously regarded as nuisance pests only.

Cross-linked polyethylene (PEX) is a flexible, chemically inert plastic tubing commonly used in plumbing and radiant heating systems. Recently, several reports of leaking PEX pipe have emerged from houses infested with overwintering L. occidentalis. Samples of leaking pipe taken from homes were found to contain multiple partial and through-wall microscopic holes, approximately $4-8 \mu \mathrm{m}$ in diameter and extending at least $2 \mathrm{~mm}$ into the pipe wall. No evidence of PEX degradation, contamination, or manufacturing defect was detected.

Received 10 January 2005. Accepted 12 May 2005.

${ }^{1}$ Present address: BIOCAP Canada Foundation, Queen's University, 156 Barrie Street, Kingston, Ontario, Canada K7L 3N6

(e-mail: sarahbates@sympatico.ca).
Several factors suggested that $L$. occidentalis may have caused the holes. First, all partial holes began at the outer surface of the pipe and extended inward, indicating that the holes were initiated from the outer surface. Second, the diameter of the holes was consistent with the diameter of seed bug stylets (approximately $30 \mu \mathrm{m})$ (PEX is elastic, hence any observed hole is expected to be smaller than the causative agent). Third, no holes or similar damage were observed in PEX pipe located in subfloors or other sealed areas that were inaccessible to overwintering bugs.

To determine whether $L$. occidentalis can damage PEX tubing, adult seed bugs were collected from seed orchards on 14-16 May 2004 in Oregon and transported to the New York State Agricultural Experiment Station, Geneva, New York. Thirteen types of PEX tubing from different manufacturers were tested for their susceptibility to damage by $L$. occidentalis. Samples included pipes that were structurally and functionally similar but manufactured by different methods (PEX-A, PEX-B, and PEXC), as well as pipe coated with UV or oxygen barriers (Table 1). In addition to PEX, three other common plumbing materials were tested: copper, polyvinyl chloride (PVC), and chlorinated polyvinyl chloride (CPVC). Pipe samples were placed in cylindrical Plexiglas ${ }^{\circledR}$ cages (25 cm long, $12 \mathrm{~cm}$ in diameter) that were sealed at the bottom with a plastic cap (Protective Industries ILL, Buffalo, New York) and enclosed with mesh at the top. The bottom of each cage was lined with a piece of filter paper (125 mm diameter). For each type of pipe, two $8-\mathrm{cm}$ sections were placed horizontally on the bottom of a cage, and one $15-\mathrm{cm}$ section was arranged at a $45^{\circ}$ angle. This arrangement allowed seed bugs access to pipes that were both horizontal and at least partly vertical (Fig. 1). The ends of the pipes were plugged with cotton balls to prevent insects from entering the pipes. Water was provided through a cotton wick placed in a 30-mL plastic cup (Polar Plastics, 


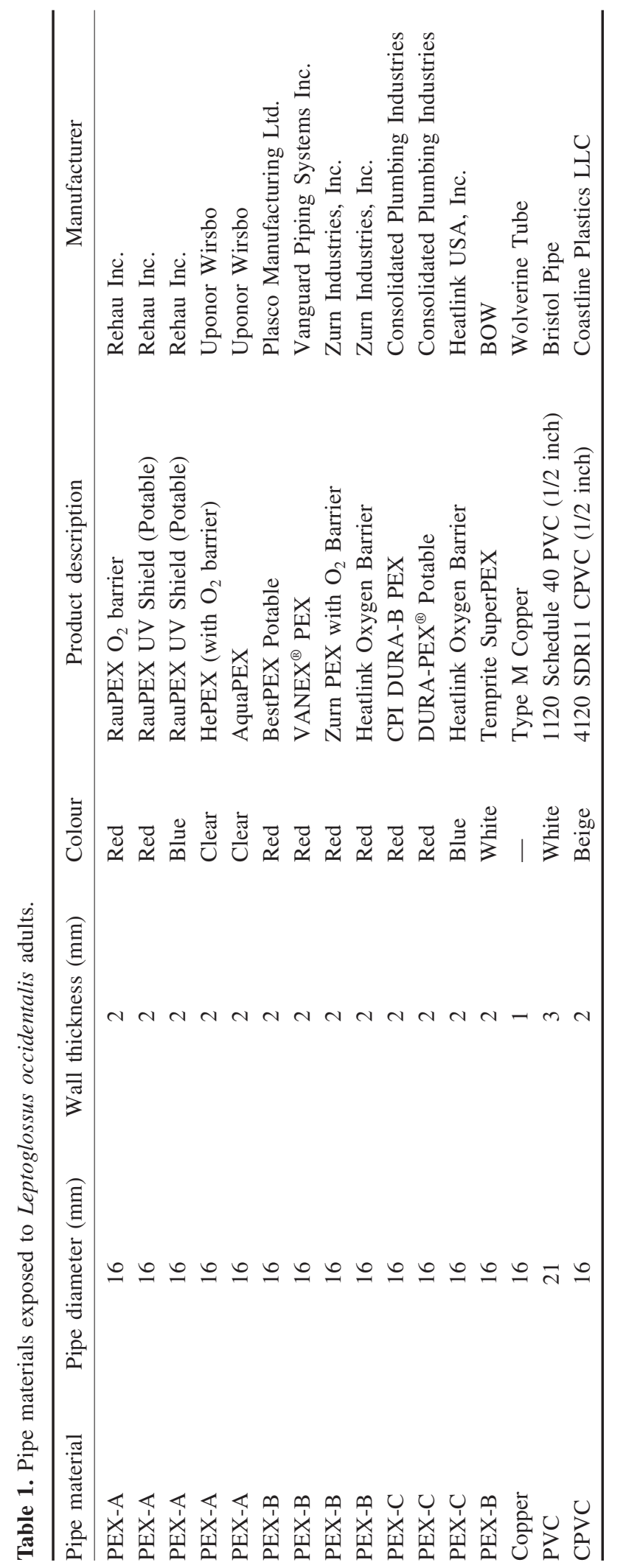

(C) 2005 Entomological Society of Canada 
Figs. 1-6. Leptoglossus occidentalis on cross-linked polyethylene (PEX) pipe and examples of damage. 1, Adult seed bug penetrating the outer surface of PEX pipe; 2, salivary sheath formed on the outer surface of coloured PEX pipe; 3, partial hole in PEX pipe obtained from a house harbouring overwintering L. occidentalis; 4, partial hole caused by L. occidentalis in the laboratory; 5 , through-wall hole in PEX pipe obtained from a house; 6 , through-wall hole obtained in the laboratory. OD, outer surface; ID, inner surface.
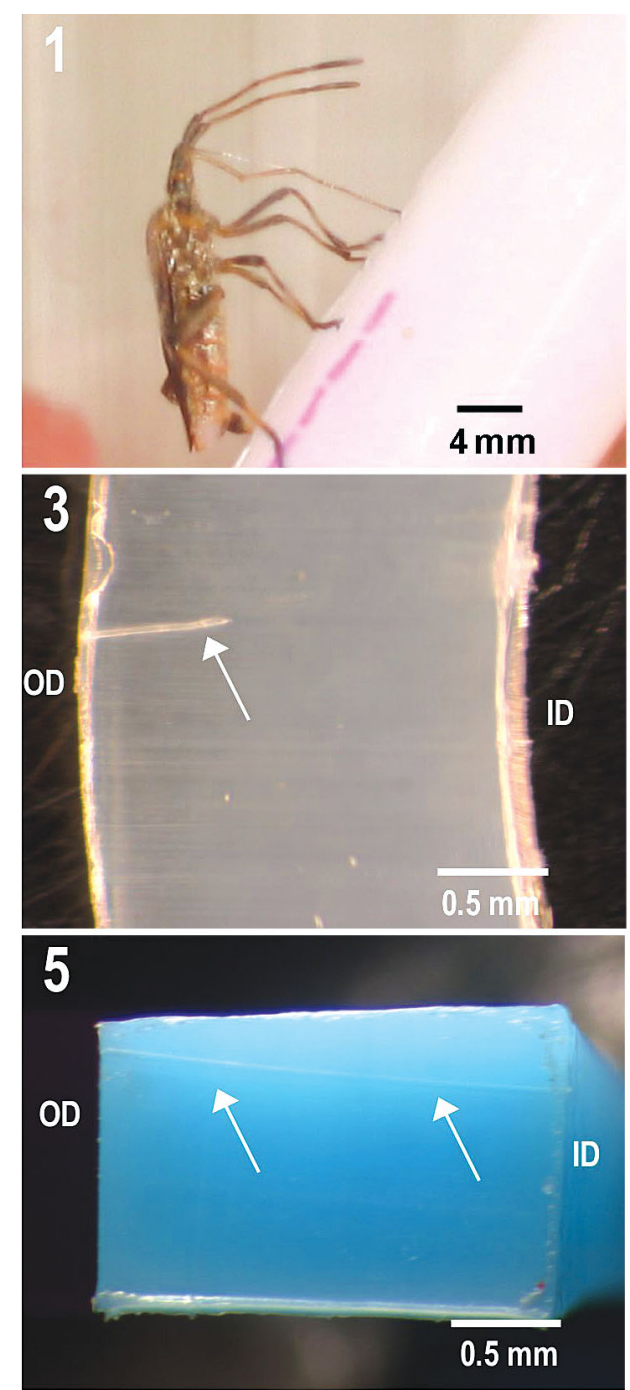

Mooresville, North Carolina) with a lid (Solo Cup Company, Urbana, Illinois). A second inverted lid was used to hold approximately $100 \mathrm{mg}$ of dry lodgepole pine seed (Pinus contorta Dougl. ex Loud; Pinaceae) as a food source. Five adults ( 3 males and 2 females) were placed in each cage. For each type of pipe, an identical control cage was set up, but no bugs were added. A small number of PEX, copper, and PVC pipes were also set up in cages without food and (or) water. All cages were maintained at room temperature and
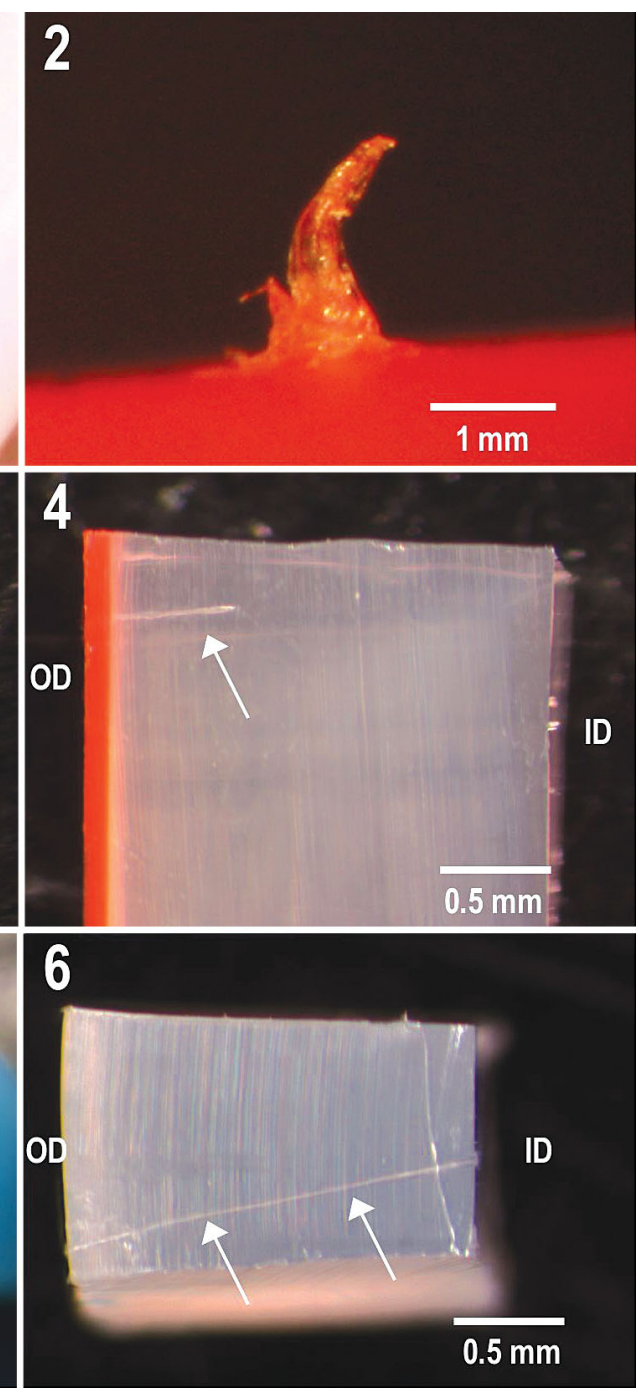

ambient photoperiod until either damage was observed on the pipe or all bugs had died. If damage was observed on a pipe sample, the pipe was removed from the experiment and the surviving bugs were transferred to remaining cages. Pipes were inspected for holes using a stereomicroscope at 10-20× magnification. To determine the depth of observed holes, pipes were sectioned with a scalpel.

Like other phytophagous members of the infraorder Pentatomomorpha (Hemiptera), L. occidentalis secretes a proteinaceous material that 
hardens to form a protective sheath around the stylets during feeding (Miles 1972). This salivary sheath forms a visible flange that remains on the surface of the material penetrated. Salivary sheaths were observed on all PEX pipes examined (Fig. 2), indicating that L. occidentalis attempted to pierce all types of PEX, regardless of chemistry, colour, or coating. The number of salivary sheaths on different pipes was variable, ranging from 2 to 23 after 1 week of exposure (additional sheaths may have been dislodged during handling of pipes). Because of the small number of insects that pipes were exposed to and differences in mortality between cages, no conclusions could be drawn regarding the relative attractiveness of different types of pipe to probing. However, from an economic perspective, minor differences in attractiveness among PEX pipes are of little importance because only one hole is required to cause damage.

Examination of PEX pipes revealed the presence of partial holes under many of the salivary sheaths in all types of PEX. Holes ranged from approximately 0.05 to $1 \mathrm{~mm}$ in length and were identical in shape, diameter, and general appearance to those observed in leaking pipes from houses harbouring L. occidentalis (Figs. 3, 4). No through-wall holes occurred. No holes or other physical defects were observed in control pipes not exposed to bugs.

Numerous salivary sheaths were also observed on PVC, CPVC, and copper pipes, and outer-surface penetration was observed beneath some of these salivary sheaths. The difficulty in sectioning these materials made it difficult to determine the depth of penetration; however, no through-wall holes occurred, as evidenced by the lack of penetration on the inner surface of the pipes. In addition, there appeared to be some chemical degradation associated with the presence of seed bug saliva and frass on these pipes. Determination of the full extent of L. occidentalis damage (both chemical and mechanical) to these materials will require further tests.

In addition to those on pipes, several salivary sheaths were also observed on many of the water and food containers, the Plexiglas cage walls, and the filter paper lining the bottom of the cages. Interestingly, extensive probing of pipes and other surfaces in the cage occurred despite the presence of food and water, indicating that this behaviour was not necessarily motivated by hunger or thirst. Somewhat surprising was the fact that none of the more than 150 holes examined extended more than $1 \mathrm{~mm}$ through the pipe wall. Removal of either food or water from cages did not result in the formation of a through-wall hole. However, when additional PEX-A pipes (selected for ease of evaluation) were subsequently exposed to bugs in a manner similar to that described above, a number of through-wall holes were observed, confirming that $L$. occidentalis can cause through-wall holes in PEX pipe (Figs. 5, $6)$. No other pipe type was subjected to further testing.

The presence of several through-wall holes in leaking pipes obtained from houses harbouring overwintering L. occidentalis suggests that the likelihood of obtaining complete penetration may be influenced by the number of insects present, the environmental conditions, or the physiological status of the bug (e.g., oligopause versus reproductively active and feeding). Additional experiments are currently under way to better identify under what conditions $L$. $O c$ cidentalis may cause through-wall holes, and whether this phenomenon extends to other species that are commonly found in man-made structures.

The ability of overwintering $L$. occidentalis to damage plumbing products represents a significant economic impact for an insect that has been hitherto considered a benign nuisance pest in man-made structures.

I thank C. Niwa, J. Berdeen, J. Riddle, R. Johnson, and R. Sniezko, USDA Forest Service, and R. Quam, Oregon Department of Forestry, for their assistance in arranging access to seed orchards, and C. Smith, Uponor Wirsbo, for technical advice and assistance. Funding for this work was provided by Uponor Wirsbo.

Bates, S.L. 2002. Detection, impact and management of the western conifer seed bug, Leptoglossus occidentalis Heidemann (Heteroptera: Coreidae), in lodgepole pine seed orchards. Ph.D. thesis, Simon Fraser University, Burnaby, British Columbia.

Bates, S.L., and Borden, J.H. 2005. Life table for Leptoglossus occidentalis Heidemann (Heteroptera: Coreidae) and prediction of damage in lodgepole pine seed orchards. Agricultural and Forest Entomology, 7: 145-151.

Bates, S.L., Lait, C.G., Borden, J.H., and Kermode, A.R. 2002. Measuring the impact of Leptoglossus occidentalis (Hemiptera: Coreidae) on seed production in lodgepole pine using an antibody-based 
assay. Journal of Economic Entomology, 95: 770777.

Blatt, S.E. 1994. An unusually large aggregation of the western conifer seed bug, Leptoglossus occidentalis (Hemiptera: Coreidae), in a manmade structure. Journal of the Entomological Society of British Columbia, 91: 71-72.

Blatt, S.E., and Borden, J.H. 1996. Evidence for a male-produced aggregation pheromone in the western conifer seed bug, Leptoglossus occidentalis Heidemann (Hemiptera: Coreidae). The Canadian Entomologist, 128: 777-778.

Gall, W.K. 1992. Further eastern range extension and host records for Leptoglossus occidentalis (Heteroptera: Coreidae): well-documented dispersal of a household nuisance. The Great Lakes Entomologist, 25: 159-171.

Hedlin, A.F., Yates, H.O., Tovar, D.C., Ebel, B.H., Koerber, T.W., and Merkel, E.P. 1981. Cone and seed insects of North American conifers. Canadian Forestry Service, USDA Forest Service, and Secretaria de Agricultura y Recursos Hidraulicos, Mexico.

Hussey, R.F. 1953. Concerning some North American Coreidae (Hemiptera). Bulletin of the Brooklyn Entomological Society, 48: 29-34.

Koerber, T.W. 1963. Leptoglossus occidentalis (Hemiptera: Coreidae), a newly discovered pest of coniferous seed. Annals of the Entomological Society of America, 56: 229-234.
Marshall, S.A. 1992. A new Ontario record of a seed eating bug (Hemiptera: Coreidae), and other examples of the role of regional insect collections in tracking changes to Ontario fauna. Proceedings of the Entomological Society of Ontario, 122: 109111.

McPherson, J.E., Packauskas, R.J., Taylor, S.J., and O'Brien, M.F. 1990. Eastern range extension of Leptoglossus occidentalis with a key to Leptoglossus species of America north of Mexico (Heteroptera: Coreidae). The Great Lakes Entomologist, 23: 99-104.

Miles, P.W. 1972. The saliva of Hemiptera. Advances in Insect Physiology, 9: 183-255.

Ridge-O'Connor, G.E. 2001. Distribution of the western conifer seed bug, Leptoglossus occidentalis Heidemann (Heteroptera: Coreidae) in Connecticut and parasitism by a tachinid fly, Trichopoda pennipes (F.) (Diptera: Tachnidae). Proceedings of the Entomological Society of Washington, 103: 364-366.

Strong, W.B., Bates, S.L., and Stoehr, M.U. 2001. Feeding by Leptoglossus occidentalis Heidemann (Hemiptera: Coreidae) reduces seed set in lodgepole pine. The Canadian Entomologist, 133: $857-865$

Taylor, S.J., Tescari, G., and Villa, M. 2001. A nearctic pest of Pinaceae accidentally introduced into Europe: Leptoglossus occidentalis (Heteroptera: Coreidae) in northern Italy. Entomological News, 112: 101-103. 